\title{
DEVELOPMENT OF COST-FUNCTIONS FOR THE REMUNERATION OF NEW ANCILLARY SERVICES IN DISTRIBUTION NETWORKS
}

\author{
Konstantinos Oureilidis ${ }^{1 *}$, Kyriaki-Nefeli Malamaki ${ }^{1}$,Spyros Gkavanoudis ${ }^{1}$, Jose L. \\ Martinez-Ramos' ${ }^{2}$ Charis Demoulias ${ }^{1}$ \\ ${ }^{I}$ Department of Electrical and Computer Engineering, Aristotle University of Thessaloniki, Thessaloniki, \\ Greece \\ ${ }^{2}$ Department of Electrical Engineering, Universidad de Sevilla, Spain \\ *oureili@yahoo.gr
}

\begin{abstract}
Keywords: ANCILLARY SERVICES, COST-FUNCTIONS， DISTRIBUTION GRID, RENEWABLE ENERGY SOURCES, SUPERCAPACITOR.
\end{abstract}

\begin{abstract}
The higher penetration of intermittent and volatile Distributed Renewable Energy Sources (DRES) in distribution grids is gradually replacing the bulk synchronous generators (SGs) of the transmission system, resulting in poor reaction after a grid event. Conventionally, in order to ensure the stable and safe operation of the electrical grid, the Transmission System Operators (TSOs) request the participation of SGs in Ancillary Services (AS) markets. On the other side, the DRES are mainly regarded as negative loads complying with certain grid codes requirements and no participation to such markets. However, new control algorithms are emerged, including the DRES operation with $P$ - $f$ droop curves, their reactive power contribution according to voltage variations, ramp-rate limitation and fault-ride-through (FRT) capability. Moreover, other support functions have also been proposed in the literature, e.g. provision of virtual inertia, power smoothing and harmonic mitigation. Such support functions, provided that they are properly quantified, can be traded in the AS markets already existing at transmission system level. This paper develops cost-functions for the procurement of the aforementioned AS in a parametric form after conducting a cost-benefit analysis per AS, considering several factors, such as the location, the size and the capability for providing the AS.
\end{abstract}

\section{Introduction}

In order to ensure the stable operation of the power system, a certain range of functions are requested by the TSOs from the conventional SGs. These functions include the frequency response, the provision of reactive power, the black start capability and various others, according to the European Network of Transmission System Operators for Electricity (ENTSO-E) [1]. However, the increase of the DRES at the local distribution level has gradual replaced the bulk generation from the large SGs, which may jeopardise the operation of the power system. As a result, a closer cooperation between the Distribution System Operators (DSOs) and TSOs is required, where the DRES will actively participate in a controllable way and offer ancillary services (AS) to their common point of connection (PCC) with the distribution grid [2].

In order to procure these AS, the TSOs have developed organized mechanisms, such as compulsory provision, bilateral contracts, tendering processes and AS markets [3]. The latter is considered as more cost-effective, as it can allow the recovery of the real costs closer to the activation of the services. Currently, the costs of the conventional SGs for providing AS can be mainly categorised in the following: $(a)$ opportunity costs, concerning the retained capacity that cannot be used for creating other value, $(b)$ efficiency costs, $(c)$ wear and tear costs regarding the faster aging of components, such as actuators and increased maintenance, and $(d)$ stability costs related to driving resources [4]. Some of these costs are related to the rotating parts of the SGs and therefore cannot be applied to converter-interfaced DRES, such as photovoltaics (PV). However, the operation with increased active power or the provision of reactive power may require an oversizing of the converters, which should be considered in the overall cost evaluation. A parameter used for determining the converter oversize is the levelized cost of energy (LCOE), which represents the average revenue per unit of electricity generated for recovering the costs of installation and operation the DRES during an assumed financial life [5].

Another aspect related to the provision of AS from DRES concerns the different nature of the renewable sources, which is volatile and intermittent. Therefore, it is difficult to relay exclusively on the renewable primary source. A prominent solution is the consideration of another secondary resource, such as a fast storage system (FSS), connected together with the DRES. For this reason, the overall cost statement cannot only regard the DRES itself, but should also include the auxiliary equipment.

Other costs may be very important for the evaluation of the provision of AS, like the opportunity cost, which corresponds to the value of the foregone production plus any other possible benefit. The market participation or the supporting mechanisms should be considered, which may differ 
significantly among the various organised markets according to the maturity of the DRES participation. For example, during the past decade, the most common remuneration scheme for the DRES was the Feed-in Tariff (FiT), where the DRES injected all the available power for a certain amount per $\mathrm{kWh}$ without any need of further control. However, the increased penetration of DRES and the related grid issues (e.g. voltage increase, fault clearing blindness, reduce of inertia, power quality issues, increased harmonic pollution, etc.) have reformed their market participation in a more active manner [6], while new grid codes of the distribution grid impose certain rules for accepting the further penetration of DRES (e.g. Puerto Rico Electric Power Authority Code [7]).

The provision of AS does not exclusively concern only the increase of the overall costs, but also the opportunity of benefits for the DRES and the distribution grid. The development of new control algorithms for the smart management of the DRES, such as the voltage control at its PCC, will allow its continuous participation without active power curtailment [8]. Other benefits may regard the effective operation of the distribution grid, e.g. with reduced power losses.

This paper deals with the development of cost-functions for AS provided by DRES, which are divided in three categories: (a) AS currently provided by SGs only to the transmission system (primary frequency response -PFR-, voltage control), (b) AS that are inherently provided by SGs (inertia, fault contribution) and (c) new AS needed due to the different nature of the DRES (power smoothing, harmonic mitigation). For all three different categories, new cost-functions should be developed in order to determine the economic participation of the DRES in AS markets and facilitate the efficient operation of the distribution grids. The use of a FSS, e.g. supercapacitor, together with an associated DC/DC converter is proposed due to the uncontrollable output of the DRES. Therefore, virtual inertia, power smoothing and fault contribution are considered to be provided by the FSS, since the timeframe of these AS is quite small and the power density of the FSS can be high. The AS of harmonic mitigation and reactive power absorption for voltage regulation purposes are suggested to be provided considering an oversizing of the DRES converter with respect to the nominal power of the DRES primary source. PFR will be provided through the operation of the DRES in a point lower than the Maximum Power Point (MPP).

\section{Cost-benefit analysis per AS}

In order to determine the cost-function of the AS, a costbenefit analysis per AS is conducted. The identified main costs categories include:

- the installation of the FSS with the associated DC/DC converter,

- the oversizing of the DRES converter,

- the increased operational losses within the DRES converter, and

- supplementary ICT costs.

The cost of the FSS is determined by taking data from literature and manufacturers for different nominal capacity and voltage level. Moreover, the cost of operational losses when providing reactive power and when operating below the MPP consider the analytical expressions developed in for the DRES converters and transformers (whenever they appear).

For the development of the cost-functions, any resulting benefits should be identified, when the AS are provided closer to the loads or closer to the source of a grid issue (e.g. fault). For example, when the voltage regulation takes place only in problematic nodes (usually the most remote ones) and not in all nodes of the distribution grid, the grid losses are decreased. Another benefit can be the decreased number of tap-changing of the distribution grid transformers when the DRES voltage control is activated.

\subsection{AS currently provided by conventional SG}

\subsubsection{Primary-frequency control (PFR)}

In order to maintain the frequency within the nominal level of $50 \mathrm{~Hz} / 60 \mathrm{~Hz}$, the TSOs should ensure that there are enough reserves to support any difference between supply and demand without jeopardising the system stability. Traditionally, this is achieved by controlling the governor of the connected SGs in the system. Since the DRES lack of such infrastructure, this AS can be enabled by constantly operating below the nominal generation. Therefore, there is no need for further investments on new devices. However, there is a constant lost opportunity cost for reserving a headroom, instead of injecting this energy in the grid.

In order to define this cost, the lost energy should be calculated as follows:

$$
E_{\text {non_inj }}=\int_{t_{\text {en }}}^{t_{\text {dis }}} P_{M P P}(t) d t-\int_{t_{\text {en }}}^{t_{d i s}} P(t) d t
$$

where $E_{n o n \_i n j}$ is the non-injected amount of energy, $P_{M P P}(t)$ is the MPP, $P(t)$ is the actual injected power, $t_{e n}$ and $t_{d i s}$ are the instances for enabling or disabling this AS. The injected power can be measured at the output of each DRES, while the MPP can be estimated by taking into consideration the technology of the DRES and weather forecast parameters (e.g. wind, solar irradiation, etc.). The cost of the non-injected energy $C_{n o n}$ inj can be calculated as:

$$
C_{\text {non_inj }}=E_{\text {non_inj }} \cdot M C P
$$

where MCP is the market clearing price of the Day-Ahead Market, which is considered the main market for selling the energy and expresses the cost of energy in $€ / \mathrm{kWh}$. However, the DRES may also receive additional compensation for outmarket supporting mechanisms, which may differ according to the national policies for the expansion of DRES [9]. Therefore, the overall opportunity cost $C_{P F R}$ can be summarised as:

$$
C_{P F R}=C_{n o n \_i n j}+C_{\text {supp_mech }}
$$

where $C_{\text {supp_mech }}$ is the lost opportunity cost from the supporting mechanisms. 


\subsubsection{Voltage control with reactive power exchange}

In the conventional distribution grids, the voltage issues are mainly identified at the last nodes of the radial networks, due to the load connections. However, with the gradual increasing penetration of DRES, the opposite effect of voltage increase is presented. In order to deal with this issue at local level, the DRES exchange reactive power at the PCC with the grid.

For providing inductive or capacitive reactive power, the DRES converters should be oversized, allowing the DRES to operate even under nominal active power of the primary source. In order to calculate the converter oversizing, the reactive power exchange should be calculated, which is location-sensitive. In [10] [11], different PV and wind scenarios are examined for determining the maximum reactive power. In the investigation of representative distribution grids [12], the maximum oversizing factor is considered $D=1.41$. This oversizing factor increases the installation costs for the DRES. However, this oversize differs significantly according to the installed capacity of the DRES. Taking into consideration prices from manufacturers [13], the DC/AC converter cost of a PV of $10 \mathrm{~kW}$ is regarded to be $160 € / \mathrm{kW}$, while for a large PV of $100 \mathrm{~kW}_{\mathrm{p}}$ is approximately $70 € / \mathrm{kW}$.

Another factor for determining the cost of the DRES concerns the increase of the converter losses for providing reactive power. In [14], the power losses $P_{\text {loss, }}$ for operating under power factor $(\mathrm{PF})$ other than unity are analytically calculated:

$$
\begin{aligned}
& P_{l o s s, v}=c_{1}+c_{2} \frac{P_{o}}{P F}+c_{3} \frac{P_{o}^{2}}{P F^{2}}+P_{o}\left(c_{4}+c_{5} \frac{P_{o}}{P F}\right) . \\
& \sqrt{\left(\frac{x_{f(p u)} \cdot P_{o}}{s_{b}}\right)^{2}+\left(\frac{x_{f(p u)} \cdot P_{o}}{s_{b}} \tan \varphi+1\right)^{2}}
\end{aligned}
$$

where $P_{o}$ is the output power, $S_{b}$ is the rated power of the $\mathrm{DC} / \mathrm{AC}$ converter, $x_{f}$ is the output filter reactance, $\varphi$ is the angle between the voltage and the current and $c_{i}, \mathrm{i}=1-5$ are coefficients selected for the various operating PF. The cost of the increased power losses $C_{\text {loss }, v}$ can be expressed by:

$$
C_{\text {loss }, v}=P_{l o s s, v} \cdot M C P
$$

Therefore, the overall cost for providing reactive power for controlling the local voltage $C_{v}$ is the following:

$$
C_{v}=C_{\text {oversize }}+C_{\text {loss }, v}
$$

where $C_{\text {oversize }}$ is the cost of oversizing the $\mathrm{DC} / \mathrm{AC}$ converter.

However, when the DRES operate with an oversized converter for exchanging reactive power certain benefits also appear. More specifically, the DSO does not need to curtail the active power output of specific DRES, which is one of the current practices for dealing with the overvoltages at distribution grids. This benefit $B_{\text {curt }}$ can be described by:

$$
B_{\text {curt }}=\left(P_{\text {nom }}-P_{\text {curt }}\right) \cdot M C P
$$

where $P_{\text {nom }}$ is the nominal power and $P_{\text {curt }}$ is the curtailed active power. The worst-case scenario regards the need for disconnection of the DRES, which corresponds to $B_{\text {curt }}=P_{\text {curt }} \cdot M C P$.

Another aspect of the converter oversize concerns the operation with reduced power losses. The reactive power exchange may not be needed on a continuous basis, therefore the DRES may operate at the nominal power with an oversized $\mathrm{DC} / \mathrm{AC}$ converter. The converter manufacturers provide such figures, where the performance ratio is maximized, as it is illustrated in Fig. 1. However, it is very difficult to approach numerically this benefit [10].

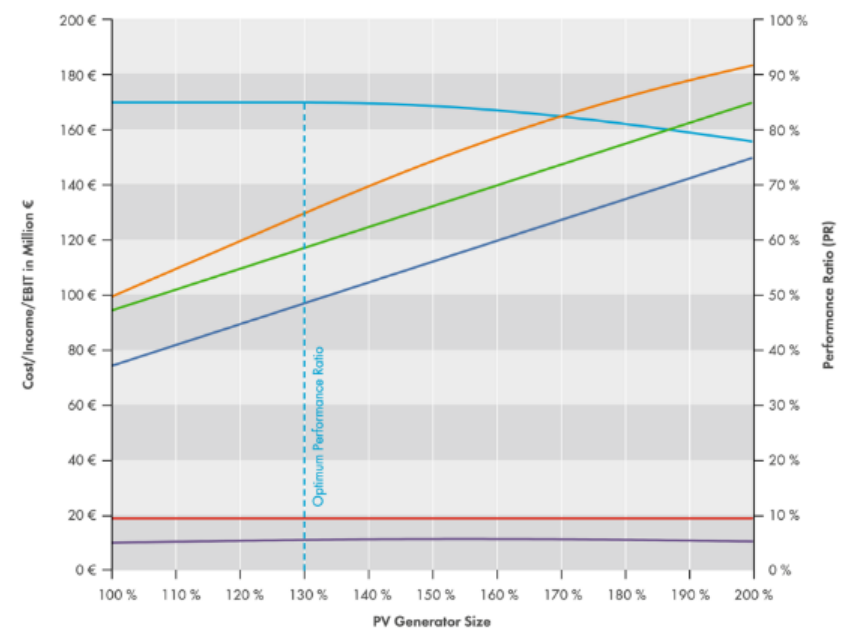

Fig. 1 Example of DC/AC oversize (red curve: fixed costs, blue curve: variable costs, green curve: sum of all costs, yellow curve: revenue, light blue curve: performance ratio)

Another benefit related to the control of reactive power for voltage regulation is the decrease of tap-changing actions in existing transformers. In order to evaluate this benefit, maintenance data are required, as the cost the of maintenance of On-Load Tap Changers (OLTC) depending on the number of tap changes [15].

\subsection{New AS inherently provided by $S G$}

\subsubsection{Virtual inertia}

Inertia is currently an inherent characteristic of the conventional SGs taking place the first few cycles after a power imbalance. The inertia is provided by the rotating masses, which absence in the converter-interfaced DRES make them inertia-less resources [16]. Therefore, new control algorithms have been developed combined with external storage systems for providing virtual (or synthetic) inertia [17]. In this paper, the case of a supercapacitor (SC) is regarded as a FSS [18].

In order to calculate the costs for virtual inertia, the cost of the SC should be analysed. This cost defers significantly according to the application, the voltage level, the total nominal stored energy, the nominal current and the lifetime cycles [19]. According to [20], for the target 2020-2030, the cost is estimated to be less than $0.01 € / F$, corresponding to an 
energy cost of less than $3 € / \mathrm{Wh}$ and a power cost of less than $0.3 € / \mathrm{W}$.

The next step to define the required stored energy for providing the virtual inertia. According to the methodology developed in [21], the SC will start releasing energy when the rate of change of frequency (ROCOF) is lower than a threshold $R_{t h l}$ and will stop releasing energy when ROCOF is higher than a threshold $R_{t h 2}$. The rate of energy release will be adjustable determined by a droop curve, as it is presented in Fig. 2. This curve can change its inclination, since $P_{M P P}$ can vary from 0 up to $P_{\text {nom: }}$ :

$$
P=\frac{P_{\text {max }}-P_{M P P}}{R_{t h 1}-R_{t h 2}} R O C O F+\frac{P_{M P P} R_{t h 1}-P_{m a x} R_{t h 2}}{R_{t h 1}-R_{t h 2}}(8)
$$

where $P_{\max }$ is the maximum short-term power capability of the converter, which can be 3-5 times the nominal power of the $\mathrm{DC} / \mathrm{AC}$ converter.

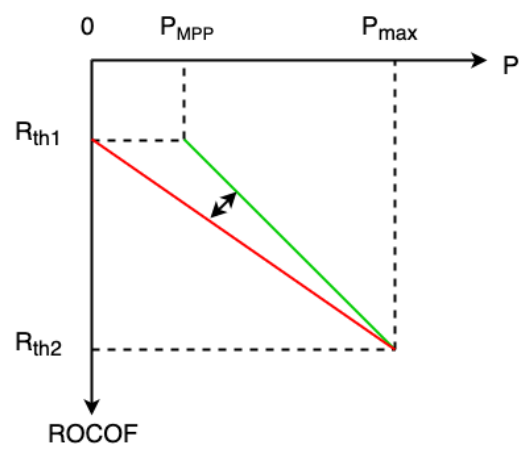

Fig. 2 Inertia droop curve

By determining the parameter $R_{t h 2}$, the inertia $H$ can be calculated:

$$
H=\frac{\Delta P}{2 \cdot R O C O F}=\frac{P_{\max }}{2 \cdot R_{t h 2}}
$$

The maximum stored energy of the SC bank corresponds to the maximum time duration, which can be regarded of about 10s. Therefore, the equation of the maximum stored energy by using (9) is equal to:

$$
E_{S C, \text { inertia }}=\int_{0}^{t} P_{\max } d \tau=2 \cdot H \cdot R_{t h 2} \cdot 10
$$

In order to determine the respective $\mathrm{SC}$ capacitance $C_{\text {finertia, }}$ the energy calculated in (10) should be used for selecting the $m$ parallel and $n$ series SC units:

$$
E_{S C, \text { inertia }}=\frac{1}{2} \cdot n \cdot m \cdot C_{f, \text { inertia }} \cdot U_{f, \max }^{2}
$$

where $U_{\max }$ is the maximum voltage of the SC unit.

The total cost of the SC does not include only the cost of SC purchase, but also the necessary connection cables and microelectronics. These costs can vary between $55 \%$ and $75 \%$ of the total SC cost. Therefore, considering a factor of $60 \%$, the cost of providing inertia $C_{\text {inertia }}$ equals to:

$$
C_{\text {inertia }}=1.6 \cdot C_{S C}
$$

\subsubsection{Fault contribution}

During faults within the distribution grid, the DRES can contribute by providing a short-circuit fault current a few times the nominal for the short period of the event. However, since the DRES may be partially or fully unavailability at the occurrence of the fault event, the use of a FSS, such as a SC bank, can be exploited.

In order to estimate the SC bank, the worst-case scenario of a high-impedance fault should be considered. In this case, the remaining voltage at the DRES terminals is relatively high, while the DRES is needed to inject a current larger than the nominal one. Assuming that the time duration is equal to $t_{\text {fault }}$ and the power needed for clearing the fault is $P_{\text {fault }}$, while the DRES is total unavailable, then the stored energy of the SC $E_{S C, f}$ is equal to:

$$
E_{S C, f}=\frac{1}{2} C_{S C, f} \cdot V_{S C}{ }^{2}=\frac{1}{\eta} \cdot \sqrt{3} \cdot I_{f} \cdot V_{h f} \cdot t_{f a u l t}
$$

where $I_{f}$ is the faulty current, $V_{h f}$ is the remaining voltage and $\eta$ is the overall efficiency of the connected DC/AC and DC/DC converters of the DRES. The faulty current depends on the location of the DRES in relation to the fault and the configuration of the protection means. When a DRES is close to the fault, the current should be higher. Regarding the total cost of the SC bank for providing increased currents during faults is estimated to be about $10 \%$ of the respective DC/AC converter [22].

\subsection{New AS due to different nature of DRES}

\subsubsection{High frequency power smoothing}

The high penetration of volatile DRES has resulted in the degradation of power quality, which is more obvious in cases of weak distribution grids. Problems can appear both in the frequency (e.g. flickering) and in the voltage (e.g. intense fluctuations). For this reason, the power smoothing by employing an external fast energy storage system, such as SC, is recommended [23].

Following recommendations from weak distribution grids, such as PREPA [7], the output power should be limited by a

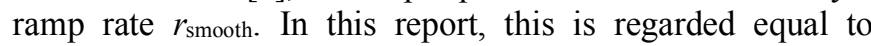
$10 \% / \mathrm{min}$. In order to calculate the SC bank for power smoothing, an indicative worst-case should be considered, such as absorbing the nominal power of the DRES $P_{\text {nom }}$ for the time period $\Delta t$ of $1 \mathrm{~min}$ :

$$
E_{S C \text {,smooth }}=r_{\text {smooth }} \cdot P_{\text {nom }} \cdot \Delta t
$$

The total cost is of SC is equal to:

$$
C_{S C, \text { smoothj }}=E_{S C, \text { smooth }} \cdot M C P
$$


In Fig. 3, the power smoothing results of a DFIG based WECS under gust event is illustrated. With red colour is the initial MPP, while with green colour is the injected smoothed power.

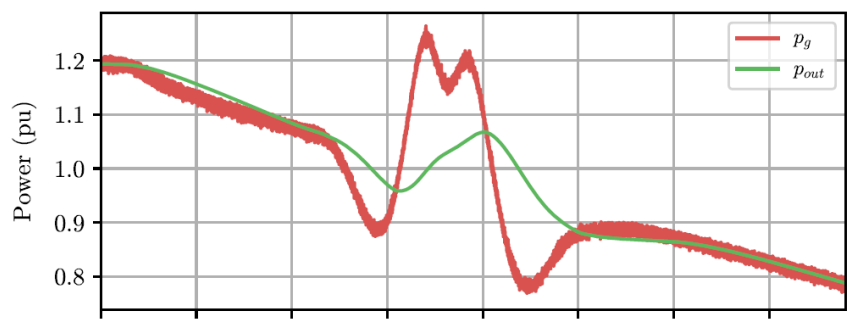

Fig. 3 Power smoothing in a PV installation $(P$ g: active power at the DC output of the PV without power smoothing control, $P_{\text {out: }}$ the output power after power smoothing)

\subsubsection{Harmonic mitigation}

Due to the high proliferation of converter-interfaced DRES, the harmonic pollution of the distribution grids has been increased. In order to the power quality, the DRES can be equipped with active filtering control algorithms and inject the properly distorted currents in order to keep the total harmonic factor within the preassigned limits of the standards, such as the EN 50160 Standard.

The costs related to this AS concern the increased power losses of the converter for providing the distorted currents. If the DC voltage and the switching frequency are considered constant, the power losses of the IGBT $P_{i}(I)$ and the diode $P_{d}(I)$ can be calculated by the following equations:

$$
\begin{aligned}
& P_{i}(I)=\theta\left[a_{i}+\left(b_{i}+c_{i} a\right) I+\left(d_{i}+e_{i} a\right) I^{2}\right] \\
& P_{d}(I)=\theta\left[a_{d}+\left(b_{d}+c_{d} a\right) I+\left(d_{d}+e_{d} a\right) I^{2}\right]
\end{aligned}
$$

where $I$ represents the output RMS current of the converter, $\theta$ is the temperature and the coefficients $a_{i, d}, b_{i, d}$ and $c_{i, d}$ are conventionally adjusted to represent the conduction and switching losses of the electronic power devices. Therefore, the aggregated power losses can be expressed by the sum of (16) and (17):

$$
P_{\text {loss }, h}=P_{i}(I)+P_{d}(I)
$$

Another cost regarding the operation of a distribution grid with currents of higher harmonic order is the increased power losses of the transformers. The power losses of the transformers are the copper losses and the magnetizing losses, while only the copper losses depend on the current [24]. The extra copper losses $P_{c u, e x t r a}$ can be estimated as:

$$
P_{c u, e x t r a}=P_{c u, n f}-P_{c u, f}
$$

where $P_{c u, n f}$ are the copper losses without active filtering and $P_{c u, f}$ are the copper losses with active filtering. Therefore, the total cost $C_{h}$ for providing harmonic mitigation is:

$$
C_{\text {loss }, h}=\left(P_{\text {loss }, h}+P_{\text {cu,extra }}\right) \cdot M C P
$$

\section{ICT cost analysis}

The costs associated with ICT refer to hardware, network, software, communication and personnel.

\subsection{Hardware/Network costs}

Within the control area of the distribution grid, each DSO should set up its own infrastructure in order to implement the control algorithms and send/receive the proper information and control signals. This infrastructure includes servers, virtual machines and forwarding switches

\subsection{Communication costs}

For ensuring the smooth operation of the distribution grid, several measurement data should be exchanged with the DSO. The common communication channels usually use the mobile communication or internet.

\subsection{Software - license costs}

In case that open source software is employed for fulfilling the ICT requirements, no extra cost for software will be applied. However, there might be servers or virtual machines, which may need licenses.

\subsection{Communication costs}

A very important part of the ICT communication concerns the encryption costs, which insures the secure operation of the grid. For this reason, new infrastructure may be required, such as establishment of a public key, generate/exchange keys, etc.

\subsection{Personnel costs}

This cost is not directly related with the provision of AS, however it should be taken into consideration. It includes the cost for the administrator in order to manage the servers or the installed ICT infrastructure. Furthermore, any training the personnel in order to use these services may also be needed.

\section{Conclusion}

This paper presents the developed parametrical cost-functions for providing AS from DRES at distribution grid level, by considering both AS already provided by the conventional SGs and new AS related to the different operation of the DRES. From the presented analysis, it can be deducted that the costs are closely related to nature of the renewable source (for example for power smoothing, inertia) and the location of the DRES (for fault contribution, voltage regulation). Other important cost factors concern the auxiliary storage system and oversize of the converters, which are required for the provision of AS. Regarding the evaluation of the benefits, the DSOs should estimate their current operation and define the possible cost deferral from the active participation of the DRES.

\section{Acknowledgements}

This work is part of and supported by the European Union, Horizon 2020 project "EASY-RES” with G.A.: 764090. 


\section{References}

[1] ENTSO-E, 'Survey on Ancillary Services Procurement, Balancing Market Design 2017', (2018).

[2] Alkandari, A., Sami, A.A., and Sami, A., 'Proposed Dso Ancillary Service Processes Considering Smart Grid Requirements', CIRED - Open Access Proceedings Journal, 2017, 2017, (1), pp. 2846-2847.

[3] Rebours, Y.G., Kirschen, D.S., Trotignon, M., and Rossignol, S., 'A Survey of Frequency and Voltage Control Ancillary Services-Part Ii: Economic Features', IEEE Transactions on Power Systems, 2007, 22, (1), pp. 358-366.

[4] Staschus, K., 'Review of German Approaches to Ancillary Services Costing and Pricing [Electricity Supply]', in, IEE Colloquium on Pricing of Ancillary Services: an International Perspective (Digest No: 1996/164), 1996.

[5] U.S. Energy Information Administration, 'Levelized Cost and Levelized Avoided Cost of New Generation Resources in the Annual Energy Outlook 2019', (2019).

[6] Pavić, I., Beus, M., Pandžić, H., Capuder, T., and Stritof, I., 'Electricity Markets Overview - Market Participation Possibilities for Renewable and Distributed Energy Resources', in, 2017 14th International Conference on the European Energy Market (EEM), 2017.

[7] V.Gevorgian, S.B., NREL, 'Review of Prepa Technical Requirements for Interconnecting Wind and Solar Generation', (2013).

[8] Kane, L. and Ault, G., 'A Review and Analysis of Renewable Energy Curtailment Schemes and Principles of Access: Transitioning Towards Business as Usual', Energy Policy, 2014, 72, pp. 67-77.

[9] Abdmouleh, Z., Alammari, R.A.M., and Gastli, A., 'Review of Policies Encouraging Renewable Energy Integration \& Best Practices', Renewable and Sustainable Energy Reviews, 2015, 45, pp. 249-262.

[10] Ali, A., Raisz, D., and Mahmoud, K., 'Optimal Oversizing of Utility-Owned Renewable Dg Inverter for Voltage Rise Prevention in Mv Distribution Systems', International Journal of Electrical Power \& Energy Systems, 2019, 105, pp. 500-513.

[11] ENTSO-E, 'High Penetration of Power Electronic Interfaced Power Sources (Hpopeips) Entso-E Guidance Document for National Implementation for Network Codes on Grid Connection', (2017).

[12] Malamaki, K.-N., Mushtaq, U., and Cvetkovic, M., 'D1.2 Report on the Definition of the Converter Reactive Power Capability, Easy-Res Project', (2019) Available online: https://cordis.europa.eu/project/ren/213757/results/en.

[13] Solar Systems Hellas, 'Pricelist, Solar System Hellas', (2020).

[14] Malamaki, K.D. and Demoulias, C.S., 'Estimation of Additional Pv Converter Losses Operating under $\mathrm{Pf} \neq 1$ Based on Manufacturer's Data at Pf $=1$, IEEE Transactions on Energy Conversion, 2019, 34, (1), pp. 540-553.

[15] Kryonidis, G.C., Theologou, N.V., Chrysochos, A.I., Demoulias, C.S., and Papagiannis, G.K., 'An Enhanced Decentralized Voltage Regulation Scheme for the Reduction of Tap Changes in Hv/Mv Transformers under High Dg Penetration', in, 2016 IEEE PES Innovative Smart Grid Technologies Conference Europe (ISGT-Europe), 2016.
[16] Magdy, G., Shabib, G., Elbaset, A.A., and Mitani, Y., 'A Novel Coordination Scheme of Virtual Inertia Control and Digital Protection for Microgrid Dynamic Security Considering High Renewable Energy Penetration', IET Renewable Power Generation, 2019, 13, (3), pp. 462-474.

[17] Fang, J., Li, H., Tang, Y., and Blaabjerg, F., 'On the Inertia of Future More-Electronics Power Systems', IEEE Journal of Emerging and Selected Topics in Power Electronics, 2019, 7, (4), pp. 2130-2146.

[18] Zhang, R., Fang, J., and Tang, Y., 'Inertia Emulation through Supercapacitor Energy Storage Systems', in, 2019 10th International Conference on Power Electronics and ECCE Asia (ICPE 2019 - ECCE Asia), 2019.

[19] Berrueta, A., Ursúa, A., Martín, I.S., Eftekhari, A., and Sanchis, P., 'Supercapacitors: Electrical Characteristics, Modeling, Applications, and Future Trends', IEEE Access, 2019, 7, pp. 50869-50896.

[20] Energy, E.A.f.S.o., 'Joint Ease/Eera Recommendation for a European Energy Storage Technology Development Roadmap Towards 2030', 2017.

[21] Demoulias, C., Gkavanoudis, S., Mauricio, J.-M., and et.al., 'D2.1 Description of Metrics Developed with Respect to Transient and Dynamic Response and Report on the Review of the Respective Current Grid Codes, Easy-Res Eu Project', (2018), Available online: https://cordis.europa.eu/project/rcn/213757/results/en.

[22] Oureilidis, K.O. and Demoulias, C.S., 'A Fault Clearing Method in Converter-Dominated Microgrids with Conventional Protection Means', IEEE Transactions on Power Electronics, 2016, 31, (6), pp. 4628-4640.

[23] Pegueroles-Queralt, J., Bianchi, F.D., and GomisBellmunt, O., 'A Power Smoothing System Based on Supercapacitors for Renewable Distributed Generation', IEEE Transactions on Industrial Electronics, 2015, 62, (1), pp. 343350.

[24] Said, D.M., Nor, K.M., and Majid, M.S., 'Analysis of Distribution Transformer Losses and Life Expectancy Using Measured Harmonic Data', in, Proceedings of 14th International Conference on Harmonics and Quality of Power - ICHQP 2010, 2010. 